\title{
Diabetes geht auf die Ohren
}

\author{
Zu Hörstörungen bei Diabetikern \\ liegen mehrere Untersuchungen vor, \\ die Befunde sind aber widersprüch- \\ lich. Um die Befunde zu objektivie- \\ ren, wurde jetzt eine systematische, \\ umfangreiche Literaturstudie durch- \\ geführt.
}

- Wissenschaftler der Nigata Universität in Japan führten Literaturrecherchen mit MEDLINE (1950-2011) und EMBASE (1974-2011) durch. Gesammelt wurden Studien, die sich mit dem Thema Hörstörungen bei Diabetikern beschäftigten. Die Hörstörung wurde begrenzt auf einen $2 \mathrm{kHz}-$ Bereich und de- finiert als progressiv, chronisch, sensorineural mit oder ohne spezifische Ursache. Die Daten wurden von zwei unabhängigen Autoren extrahiert. Die Odds ratio der Hörstörung wurden berechnet.

Aus 13 vergleichbaren Studien konnten Daten von 20194 Teilnehmern und 7377 Fällen ausgewertet werden. Demnach haben Diabetiker mehr als doppelt so häufig Hörstörungen (OR 2,15; $95 \%-K I=1,72-2,68)$ wie die Nicht-Diabetiker. Diese höhere Assoziation zwischen Diabetes und Hörstörungen wird weder signifikant beeinflusst vom Alter und Geschlecht $(\mathrm{P}=0,68)$ noch von chronischer Lärmexposition $(\mathrm{P}=0,19)$

\begin{abstract}
- C. Horikawa et al.
Diabetes and risk of hearing impairment in adults: A meta-analysis. First published $12 \mathrm{Nov}$ 2012 in J Clin Endocrinol Metab; doi:10.1210/ jc.2012-2119
\end{abstract}

\section{Kommentar}

Unabhängig vom Alter haben die Diabetiker mehr als doppelt so häufig Hörstörungen wie die Nicht-Diabetiker. Die Hörschäden könnten durch Gefäßschäden, durch die hohen Blutglukosewerte und direkte Nervenschäden bedingt sein, so die Autoren.

K. MALBERG =

\section{Vitamin-D-Mangel als Mutter vieler Übel}

\section{Bei Personen mit einer Vitamin-D- Konzentration unter $20 \mathrm{ng} / \mathrm{ml}$ kommt es statistisch betrachtet zu einem An- stieg von Myokardinfarkten, Krebser- krankungen, Schenkelhalsfrakturen und Todesfällen.}

- In den letzten Jahren ist der VitaminD-Mangel nicht nur im Zusammenhang mit der Entwicklung von Osteoporose und Osteomalazie, sondern über die

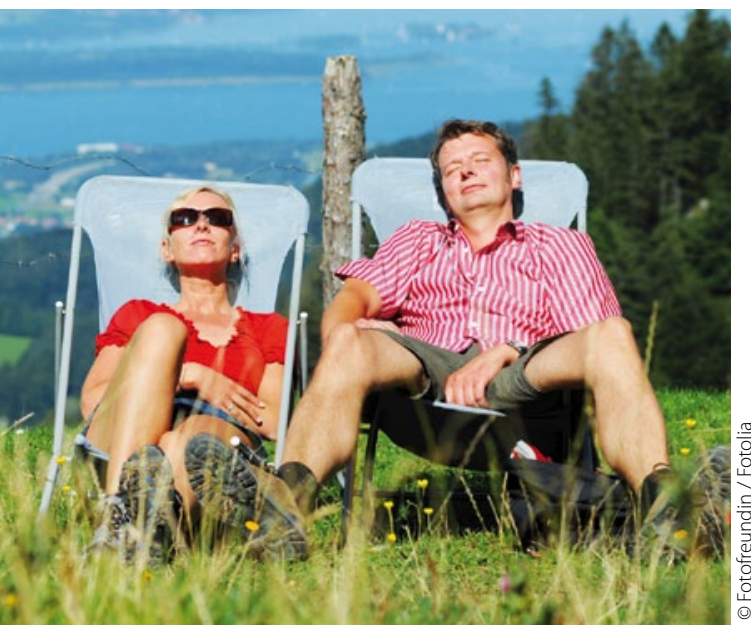

Ein Sonnenbad reicht als Schutz vor Vitamin-D-Mangel nicht aus. sog. pleiotropen Effekte auch mit einer Fülle von anderen Krankheiten in Verbindung gebracht worden. Die Konzentration von 25-Hydroxyvitamin D in der Zirkulation spiegelt die Gesamt-Vitamin-D-Aufnahme durch Synthese der Haut und diätetische Zufuhr wider. Anhand von Markern des Knochen- und Mineralstoffwechsels wie Knochendichte, intestinale Kalziumsabsorption und Parathormon-Konzentration hat man versucht, optimale Spiegel von Vitamin D zur Prävention von Knochenerkrankungen herauszuarbeiten.

In der Cardiovascular Health Study, einer prospektiven Kohortenstudie mit
1621 kaukasischen Probanden im Durchschnittsalter von 74 Jahren, hat man nun einen weiteren Blickwinkel angelegt. Im Verlauf einer im Median elfjährigen Beobachtungsdauer kam es bei 1018 Probanden (63\%) zum kombinierten Endpunkt von Schenkelhalsfraktur, Myokardinfarkt, Krebserkrankung oder Tod. Im einzelnen traten 137 Schenkelhalsfrakturen, 186 Myokardinfarkte, 335 Karzinome und 360 Todesfälle auf. Die Vitamin-D-Konzentration, ab der es zu einem signifikanten Anstieg des Endpunkts kam, lag im Winter bei $17 \mathrm{ng} / \mathrm{ml}$, im Frühling bei $20 \mathrm{ng} / \mathrm{ml}$, im Sommer bei $24 \mathrm{ng} / \mathrm{ml}$ und im Herbst bei $22 \mathrm{ng} / \mathrm{ml}$.

\section{Kommentar}

Wir müssen erkennen, dass es nördlich des 40. Breitengrades auch der weißen Rasse nicht gelingt, ausreichende Vitamin DKonzentrationen durch Sonnenbestrahlung der Haut zustande zu bringen. Die Sorge vor Hautkrebs und die breite Anwendung von Sonnenschutzmitteln mit hohem Lichtschutzfaktor hat diese Entwicklung noch aggraviert. Eine gelegentliche Spiegelbestimmung und eine Substitution mit Vitamin
$D$ bis zum Erreichen eines Spiegels von wenigstens $20 \mathrm{ng} / \mathrm{ml}$ erscheinen heute als vernünftige präventive Maßnahmen.

H. S. FÜESSL -

\footnotetext{
- I. H. de Boer et al.

Serum 25-hydroxyvitamin D concentration and risk for major clinical disease events in a community-based population of older adults. Annals Intern Med. 2012; 156: 627-634
} 